\title{
Determinants of Quality of Life After Lung Transplantation
}

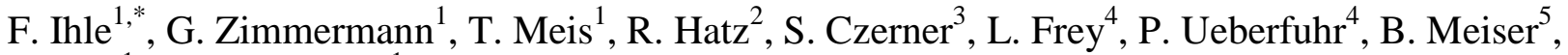 \\ J. Behr ${ }^{1}$ and C. Neurohr ${ }^{1}$, for the Munich Lung Transplant Group
}

\author{
${ }^{1}$ Department of Internal Medicine V, University of Munich, Germany, Comprehensive Pneumology Center, Member of \\ the German Center for Lung Research \\ ${ }^{2}$ Department of Surgery, Klinikum Grosshadern, Ludwig Maximilians University, Munich, Germany \\ ${ }^{3}$ Department of Anesthesiology, Klinikum Grosshadern, Ludwig Maximilians University, Munich, Germany \\ ${ }^{4}$ Department of Cardiac Surgery, Klinikum Grosshadern, Ludwig Maximilians University, Munich, Germany \\ ${ }^{5}$ Transplant Center Munich, Klinikum Grosshadern, Ludwig Maximilians University, Munich, Germany
}

\begin{abstract}
Background: The purpose of this study was to examine clinical and non- clinical determinants of quality of life (QoL) in lung transplant recipients (LTR).

Methods: QoL was measured cross-sectional in 152 LTR (4.5 \pm 3.2 years after lung transplantation [LTx]; 95 [63\%] double LTx; 80 [53\%] female; age 50 \pm 11.9 years; 28 [18\%] bronchiolitis obliterans syndrome (BOS) stage $\geq 1$ ) using the SF-36, the "Quality of Life Profile for Chronic Diseases Questionnaire" as well as the "St. Georges` Respiratory Questionnaire". Gender, age, body mass index (BMI), time after LTx, procedure type, underlying disease, marital- and professional status and exercise capacity (6-minute walk test, 6MWT) were tested for their predictive value by non-parametric significance tests and ANOVA and ANCOVA.

Results: There was a significant correlation with higher physical QoL scores for age $<48$ years $(\mathrm{p}<0.05)$, a BMI of 21.0 $25.2 \mathrm{~kg} / \mathrm{m}^{2}(\mathrm{p}<0.05)$, a 6 MWT $\geq 430 \mathrm{~m}(\mathrm{p}<0.001)$, for cystic fibrosis patients $(\mathrm{p}<0.05)$ without $\mathrm{BOS}(\mathrm{p}<0.05)$ and who go to work $(p=0.018)$. Females boasted a superior social health $(p=0.04)$ and less respiratory symptoms $(p=0.023)$. Double LTx was a significant predictor for both, mental and physical health $(\mathrm{p}<0.05)$. Subsequent analysis of covariance revealed only BMI $(p=0.024)$, BOS stage $(p<0.001)$, underlying disease $(p=0.01)$ and exercise capacity according to 6MWT $(\mathrm{p}<0.001)$ as significant predictors for QoL independent of age.

Conclusion: The study results suggest that returning to normal BMI and improving exercise capacity seem to be important therapeutic approaches to enhance QoL after LTx. Future investigations should focus on prophylaxis and therapy of BOS to further optimize QoL after LTx.
\end{abstract}

Keywords: Lung transplantation, quality of life, bronchiolitis obliterans syndrome.

\section{INTRODUCTION}

Patient and graft survival rates following lung transplantation (LTx) increased over the last years [1]. Following this success in prolonging life expectancy of lung transplant recipients (LTR), more attention has been paid to patients health-related quality of life (HRQOL). Previous reports have shown that HRQOL is good or even excellent within the first year after LTx compared to before LTx [2, 3]. Beyond 2 years after LTx, HRQOL is adversely affected by potential treatment-related side-effects, infection, acute and chronic rejection [4].

*Address correspondence to this author at the Department of Internal Medicine V, Klinikum Grosshadern, Ludwig Maximilians University, Munich, Germany; Tel: (+)4989440073090; Fax: (+)49440078877;

E-mail: franziska.ihle@med.uni-muenchen.de
Various clinical studies investigated psychological problems, physical condition, diagnosis and individual characteristics for their potential to influence HRQOL and elucidated debatable values for these variables [4-7]. However, clinical and non-clinical predictors of HRQOL are still controversial. Moreover, investigations are limited by small sample sizes and inadequately described sampling strategies using different instruments.

The objectives of this study were to determine the impact of clinical-, individual-, sociodemographic- and physical determinants (Table 1) on lung transplant recipients perceptions of HRQOL within a large recipient cohort by using a comprehensive tool of generic- and disease specific questionnaires. Furthermore, multivariate analysis of variance and covariance included patients age (a known predictor for HRQOL) and identified the most relevant questionnaire to adress determinants of HRQOL. 
Table 1. Categories of determinants of HRQOL after LTx.

\begin{tabular}{|c|c|}
\hline Category & Determinants \\
\hline patients characteristics & gender \\
\hline & age [years] \\
\hline & body mass index \\
\hline clinical & time after LTx [years] \\
\hline & procedure type \\
\hline sociodemographic & underlying disease \\
\hline & BOS stage \\
\hline exercise capacity & marital status \\
\hline
\end{tabular}

HRQOL: health-related quality of life; BOS: bronchiolitis obliterans syndrome; LTx: lung transplantation; 6MWT: 6-minute walk test.

\section{MATERIALS AND METHODS}

Over a period of one year (starting May 1st, 2007), 152 LTR (72 males, 95 double lung transplantation, 9.9 \pm 3.3 years after LTx) of the Munich LTx follow up program were consecutively enrolled in this cross-sectional study. During regular outpatient clinical visits patients were assessed by standardized HRQOL questionnaires and completed a submaximal (6-minute walk test) physical examination in order to determine physical performance.

All participants completed all parts of the study and were included in the evaluation. The subjects agreed in written consent, according to the protocol approved by the ethics committee of the medical faculty of the Ludwig Maximilians University, Munich, Germany.

\section{Health Related Quality of Life}

HRQOL data were assessed using three questionnaires: the "Short Form 36 Health Survey" (SF-36) and the "Quality of Life Profile for Chronic Diseases" (PLC) as generic instruments and the "St. George's Respiratory Questionnaire" (SGRQ) as a lung specific questionnaire as described previously in detail [8-11].

\section{Statistics}

Data analysis was performed using Microsoft Excel 2013 (Microsoft ${ }^{\circledR}$ Office Professional, Microsoft Corporation, San Francisco) and SPSS version 21.0 (SPSS Inc., Chicago, IL). To analyze the influence of determinants on HRQOL the Mann Whitney u-test was used for two-sample-testing and the Kruskall Wallis h-test for multi-sample-testing. Multivariate data analyses included analysis of variance (ANOVA) and-covariance (ANCOVA). A p-value of $<0.05$ was considered significant.

\section{RESULTS}

Table 2 shows the baseline characteristics of the study population.
Table 2. Baseline characteristics of the study population.

\begin{tabular}{|c|c|}
\hline LTR [n=152] & \\
\hline age [years] & $50 \pm 11.9$ \\
\hline $\min$ & 23 \\
\hline $\max$ & 73 \\
\hline \multicolumn{2}{|l|}{ gender } \\
\hline male & $72[47.7 \%]$ \\
\hline female & $80[52.5 \%]$ \\
\hline \multicolumn{2}{|l|}{ underlying disease } \\
\hline IPF & $59[38.8 \%]$ \\
\hline COPD & $26[17.1 \%]$ \\
\hline $\mathrm{CF}$ & $26[17.1 \%]$ \\
\hline other & $41[27 \%]$ \\
\hline \multicolumn{2}{|l|}{ procedure type } \\
\hline SLTx & $57[37.5 \%]$ \\
\hline DLTx & $95[62.5 \%]$ \\
\hline time after $\mathbf{L T} x$ & $3.9 \pm 3.3$ \\
\hline $\min$ & 0.17 \\
\hline $\max$ & 16 \\
\hline \multicolumn{2}{|l|}{ BOS stage } \\
\hline BOS 0/0p & 124 [81.5\%] \\
\hline $\mathrm{BOS} \geq 1$ & $28[18.5 \%]$ \\
\hline BMI & $23 \pm 4.2$ \\
\hline $\min$ & 16 \\
\hline $\max$ & 37.9 \\
\hline \multicolumn{2}{|l|}{ marital status } \\
\hline living alone & $49[32.2 \%]$ \\
\hline \multicolumn{2}{|l|}{ living together with } \\
\hline family/cohabitant & $103[67.8 \%]$ \\
\hline \multicolumn{2}{|l|}{ professional status } \\
\hline go to work & $19[12.5 \%]$ \\
\hline don`t go to work & 133 [87.5\%] \\
\hline
\end{tabular}

LTR: lung transplant recipients; IPF: idiopathic pulmonary fibrosis; COPD: chronic obstructive pulmonal disease, CF: cystic fibrosis; SLTx: single lung transplantation; DLTx: double lung transplantation; LTx: lung transplantation; BOS: bronchiolitis obliterans syndrome, BMI: body mass index, min: minimum, max: maximum

[mean \pm standard deviation]

\section{Patients Characteristics}

Regarding gender specific HRQOL differences, female LTR $(\mathrm{n}=80)$ described their "sociability" according to PLC $(p=0.046)$ significantly better than male LTR as well as their 
respiratory "symptoms" according to SGRQ ( $\mathrm{p}=0.023$; Table 3).

Secondly, "age" was tested for its statistical significance on HRQOL in LTR (Table 4). For this purpose the study population was split into three groups: age 23-48 years $(n=52)$, age $48-59$ years $(n=57)$ and age 59-73 years $(n=43)$. Younger LTR between 23 and 48 years were found to have a significantly better HRQOL in up to 10 of 17 HRQOL scales

Table 3. Bivariate determinants of quality of life after lung transplantation.

\begin{tabular}{|c|c|c|c|}
\hline & SF36 & PLC & SGRQ \\
\hline \multicolumn{4}{|l|}{ gender } \\
\hline female vs. male & & *Soc & $*$ Sym \\
\hline \multicolumn{4}{|l|}{ procedure type } \\
\hline DLTx vs. SLTx & $* \mathrm{PhyFu},{ }^{*} \mathrm{GeMeHe}, * \mathrm{MeHe}$ & *ExCap, *AbEnRe, *Pos, *Soc & *Sym, *Act, *Imp \\
\hline \multicolumn{4}{|l|}{ BOS stage } \\
\hline $0 / 0$ vs. $\geq 1$ & *PhyFu, *GeMeHe & $*$ Soc & ${ }^{*}$ Sym, $*$ Act, ${ }^{*} \operatorname{Imp}$ \\
\hline \multicolumn{4}{|l|}{ professional status } \\
\hline work vs. no work & *PhyFu, *RoLiPhy, *Pain, *GeMeHe, *MeHe & *ExCap, *AbEnRe, *Pos, *Neg, *Soc & $*$ Act, $* \operatorname{Imp}$ \\
\hline
\end{tabular}

*p $<0.05$

DLTX, double lung transplantation; SLTx, single lung transplantation; BOS, bronchiolitis obliterans syndrome; SF36, short form 36 health questionnaire, PLC, profile of chronic diseases questionnaire; SGRQ, st.geroges`respiratory questionnaire, PhyFu, physical functioning; GeMeHe, general medical health; $\mathrm{MeHe}$, mental health; RoLiPhy, role limitations physical; Soc, sociability, ExCap, exercise capacity, AbEnRe, ability to enjoy and relax; Pos, positive mood; Neg, negative mood; Sym, symptoms; Act, activity; Imp, impacts.

Table 4. Multivariate determinants of quality of life after lung transplantation.

\begin{tabular}{|c|c|c|c|}
\hline & SF36 & PLC & SGRQ \\
\hline \multicolumn{4}{|l|}{ age [years] } \\
\hline$<48$ a vs. $48-59 a$ & *PhyFu & *ExCap, *AbEnRe, *Soc & *Sym, *Act. *Imp \\
\hline$<48 \mathrm{a}$ vs. $>59 \mathrm{a}$ & $* \mathrm{PhyFu}, *$ RoLiPhy, *Vit & ${ }^{*}$ ExCap, ${ }^{*}$ AbEnRe, $*$ Soc, $*$ Pos & *Sym, *Act, *Imp \\
\hline \multicolumn{4}{|l|}{ BMI $\left[\mathrm{kg}^{*} \mathbf{m}^{-2}\right]$} \\
\hline nw vs. ow & *PhyFu & & $*$ Act, $* \operatorname{Imp}$ \\
\hline uw/nw vs. ow & & & *Sym \\
\hline \multicolumn{4}{|l|}{ time after LTx [years] } \\
\hline$<1$ a vs. $1-3 a$ & *GeMeHe & $*$ Neg & \\
\hline$<1 \mathrm{a}$ va. $>5 \mathrm{a}$ & & $* \mathrm{Neg}$ & \\
\hline \multicolumn{4}{|l|}{ underlying disease } \\
\hline CF vs. IPF & *PhyFu, *RoLiPhy, *Vit & *ExCap, *AbEnRe, *Pos, *Soc & *Sym, *Act, *Imp \\
\hline CF vs. COPD & ${ }^{*} \mathrm{PhyFu},{ }^{*} \mathrm{RoLiPhy}, * \mathrm{Vit}, * \mathrm{MeHe}$ & $*$ ExCap, *AbEnRe, *Pos, *Soc & ${ }^{*}$ Sym, $*$ Act, $* \operatorname{Imp}$ \\
\hline \multicolumn{4}{|l|}{ 6MWT [meter] } \\
\hline$<430 \mathrm{~m}$ vs. $430-500 \mathrm{~m}$ & *PhyFu, *RoLiPhy, *Vit, *Soc, *RoLiEm & *ExCap, *AbEnRe, *Soc, *Pos, *Neg & $*$ Act, ${ }^{*} \operatorname{Imp}$ \\
\hline$<430 \mathrm{~m}$ vs. $>500 \mathrm{~m}$ & $\begin{array}{c}* \text { PhyFu, *RoLiPhy, } * \text { Vit, }{ }^{*} \text { Soc, } * \text { RoLiEm, } * \text { Pain } \\
* \text { MeHe, }{ }^{\text {GeMeHe }}\end{array}$ & $*$ ExCap, *AbEnRe, *Soc, *Pos, *Neg & *Act, ${ }^{*} \operatorname{Imp},{ }^{*}$ Sym \\
\hline $430-500 \mathrm{~m}$ vs. $>500 \mathrm{~m}$ & $* \mathrm{PhyFu}, * \mathrm{GeMeHe}$ & *ExCap, *AbEnRe, *Soc & *Act, ${ }^{*}$ Imp, $*$ Sym \\
\hline
\end{tabular}

$* \mathrm{p}<0.05$

nw, normal weight; ow, overweight; uw, underweight; LTx, lung transplantation; CF, cystic fibrosis; IPF, idiopathic pulmonary fibrosis; COPD, chronic obstructive pulmonal disease; 6MWT, 6-minute walk test; SF36, short form 36 health questionnaire, PLC, profile of chronic diseases questionnaire; SGRQ, st.geroges`respiratory questionnaire, PhyFu, physical functioning; Vit, vitality; RoLiEm, role limitations emotional; GeMeHe, general medical health; MeHe, mental health; RoLiPhy, role limitations physical; Soc, sociability, ExCap, exercise capacity, AbEnRe, ability to enjoy and relax; Pos, positive mood; Neg, negative mood; Sym, symptoms; Act, activity; Imp, impacts. 
in comparison to patients beyond 48 years $(\mathrm{p}<0.05$; Table 4$)$. Recipients in the age band of 48 to 73 years showed an equally good HRQOL ( $\mathrm{p}>0.05$ ).

Since patients following LTx often show weight fluctuations, the impact of "body mass index" (BMI) on HRQOL was analysed (Table 4). According to the definition of BMI, LTR were divided into "underweight" $\left(\mathrm{BMI}<21 \mathrm{~kg}^{*}\{\mathrm{~m}\}^{2}\right)^{-1}, \mathrm{n}=50$ ), "normal weight" (BMI 21-25.2 $\left.\mathrm{kg} *\left\{\mathrm{~m}^{2}\right\}^{-1}, \mathrm{n}=48\right)$ and "overweight" (BMI $>25.2 \mathrm{~kg} *\left\{\mathrm{~m}^{2}\right\}^{-1}$, $\mathrm{n}=54$ ). Compared to overweight LTR, patients with normal weight showed a significantly better "physical functioning" $(\mathrm{p}=0.016$; SF-36) and a superior lung specific HRQOL according to SGRQ $(p<0.05$; Table 4). In contrast, underweight patients' respiratory "symptoms" $(\mathrm{p}=0.015$; SGRQ) were significantly reduced in comparison to overweight patients (Table 4). No statistical significance between the study groups were detected for PLC ( $p>0.05)$.

Furthermore, HRQOL was evaluated by "time after LTx" (Table 4). Four patient groups were designed: less than 1 year $(n=46), 1-3$ years $(n=38), 3-5$ years $(n=30)$ and above 5 years $(n=38)$ following LTx. Patients within the first year after LTx were found to have a significantly better "general medical health" ( $\mathrm{p}=0.048$; SF-36), "negative mood" (meaning "better mood"; $\mathrm{p}=0.035$; PLC) and "affiliation" $(\mathrm{p}=0.045 ;$ PLC $)$ in contrast to LTR between $1-3$ years after LTx and a less "negative mood" (meaning "better mood"; $\mathrm{p}=0.02$ ) in contrast to patients above 5 years posttransplantation (Table 4). No significant HRQOL differences among the study groups were analysed for SGRQ $(\mathrm{p}>0.05)$

\section{Clinical Determinants}

Regarding the impact of "procedure type" on quality of life the study group was scaled in "single LTR" $(\mathrm{n}=57)$ and "double LTR" (n=95). Patients after double LTx were found to have a significantly better HRQOL in 10 of $17 \mathrm{HRQOL}$ sub-scales in both, physical and psychosocial domains, compared to single LTR ( $<<0.05$; Table 3 ).

Furthermore, "underlying disease" was tested for its statistical significance on HRQOL (Table 4). Patients were divided into three categories: cystic fibrosis $(\mathrm{CF}, \mathrm{n}=26)$, idiopathic pulmonary fibrosis (IPF, $n=59$ ) and chronic obstructive pulmonary disease (COPD, $n=26$ ). No significant differences were found between IPF- and COPD patients ( $>>0.05)$. Consequently, both groups described their quality of life as equally good. In contrast, CF patients described their HRQOL in 10 of 17 HRQOL scales significantly superior with respect to physical domains in comparison to IPF- and COPD patients ( $\mathrm{p}<0.05$; Table 4).

Concerning the influence of "BOS stage" on HRQOL, LTR with BOS stage $0 / 0 \mathrm{p}$ had a significantly higher HRQOL in 11 of 17 scales, especially in physical and social domains than LTR with BOS stage $>1 \quad(\mathrm{p}<0.05$; Table 3). Interestingly, BOS did not seem to have any influence on psychological HRQOL domains.

\section{Sociodemographic Determinants}

Regarding sociodemographic determinants, marital status did not have any impact on HRQOL following LTx.

Out of 152 LTR, only 19 (12.5\%) go to work (full time, part time or professional training). LTR having a job described their HRQOL significantly better in 5 of 8 scales of SF-36 ( $p<0.05)$, in 5 of 6 scales of PLC $(p<0.05)$ and in 2 of 3 scales of SGRQ $(p<0.05)$, indicating a higher quality of life compared to LTR without work (Table 3 ).

\section{Exercise Capacity}

The prevalence of exercise capacity on HRQOL was defined using the 6-minute walk distance (Table 4).

Table 5. Multivariate analysis.

5a. ANOVA: Analysis of variance.

\begin{tabular}{|c|c|c|c|}
\hline Determinant & Statistical Significance & & SGRQ \\
\hline \hline Sender & SF-36 & PLC & $\mathrm{p}=0.085$ \\
\hline age & $\mathrm{p}=0.04^{*}$ & $\mathrm{p}=0.01^{*}$ & $\mathrm{p}<0.001^{*}$ \\
\hline BMI & $\mathrm{p}=0.001^{*}$ & $\mathrm{p}=0.007^{*}$ & $\mathrm{p}=0.094$ \\
\hline time after LTx & $\mathrm{p}=0.008^{*}$ & $\mathrm{p}=0.699$ & $\mathrm{p}=0.466$ \\
\hline procedure type & $\mathrm{p}=0.616$ & $\mathrm{p}=0.721$ & $\mathrm{p}<0.001^{*}$ \\
\hline underlying disease & $\mathrm{p}=0.006^{*}$ & $\mathrm{p}=0.117$ & $\mathrm{p}<0.001^{*}$ \\
\hline BOS stage & $\mathrm{p}<0.001^{*}$ & $\mathrm{p}=0.102$ & $\mathrm{p}<0.001^{*}$ \\
\hline marital status & $\mathrm{p}<0.001^{*}$ & $\mathrm{p}<0.001^{*}$ & $\mathrm{p}=0.390$ \\
\hline professional status & $\mathrm{p}=0.696$ & $\mathrm{p}=0.013^{*}$ & $\mathrm{p}=0.031^{*}$ \\
\hline 6MWT & $\mathrm{p}=0.018^{*}$ & $\mathrm{p}=0.004^{*}$ & $\mathrm{p}<0.001^{*}$ \\
\hline
\end{tabular}

SF-36: short form-36-health questionnaire; PLC: profile of chronic diseases questionnaire; SGRQ: St.Geogre`s Respiratory Questionnaire; BMI: body-mass index; BOS: bronchiolitis obliterans syndrome; LTx: lung transplantation; 6MWT: 6-minute walk test. $* \mathrm{p}<0.05$ 


\section{5b. ANCOVA: Analysis of co-variance.}

\begin{tabular}{|c|c|c|c|}
\hline Determinant & Statistical Significance & & PLC \\
\hline & SF-36 & $\mathrm{p}=0.018^{*}$ & $\mathrm{p}=0.158$ \\
\hline gender & $\mathrm{p}=0.932$ & $\mathrm{p}=0.542$ & $\mathrm{p}=0.186$ \\
\hline BMI & $\mathrm{p}=0.024^{*}$ & $\mathrm{p}=0.704$ & $\mathrm{p}=0.711$ \\
\hline time after LTx & $\mathrm{p}=0.541$ & $\mathrm{p}=0.763$ & $\mathrm{p}=0.046^{*}$ \\
\hline procedure type & $\mathrm{p}=0.297$ & $\mathrm{p}=0.422$ & $\mathrm{p}=0.059$ \\
\hline underlying disease & $\mathrm{p}=0.01^{*}$ & $\mathrm{p}<0.001^{*}$ & $\mathrm{p}<0.001^{*}$ \\
\hline BOS stage & $\mathrm{p}<0.001^{*}$ & $\mathrm{p}=0.034^{*}$ & $\mathrm{p}=0.39$ \\
\hline marital status & $\mathrm{p}=0.844$ & $\mathrm{p}=0.026^{*}$ & $\mathrm{p}=0.155$ \\
\hline professional status & $\mathrm{p}=0.085$ & $\mathrm{p}<0.001^{*}$ & $<0.001^{*}$ \\
\hline 6 MWT & $\mathrm{p}<0.001^{*}$ & & \\
\hline
\end{tabular}

SF-36: short form-36-health questionnaire; PLC: profile of chronic diseases questionnaire; SGRQ: St.Geogre`s Respiratory Questionnaire; BMI: body-mass index; BOS: bronchiolitis obliterans syndrome; LTx: lung transplantation; 6MWT: 6-minute walk test.

$* \mathrm{p}<0.05$

Therefore a reduced sample size of $n=146$ was evaluated: 100 to 430 meters for "minor performance" $(n=51), 431$ to 500 meters for "moderate performance" $(n=49)$ and 501 to 800 meters for "high performance" $(n=46)$.

Compared to "minor performance" patients, LTR with "high performance" were found to have a significantly enhanced HRQOL in all questionnaires $(p<0.05)$ - except "affiliation"( $p>0.05)$ of PLC (Table 4). Patients with "moderate performance" demonstrated a superior HRQOL in 12 of 17 HRQOL scales compared to the "minor performance" group $(\mathrm{p}<0.05)$ and an inferior HRQOL in 5 of 17 scales compared to the "high performance" group $(\mathrm{p}<0.05$; Table 4).

\section{Multivariate Analysis}

Multivariate analysis of variance (ANOVA) revealed SF36 as most sensitive questionnaire to represent the overall impact of different determinants on HRQOL: out of 10 variables, 8 are considered statistically significant $(\mathrm{p}<0.05$; Table 5a). On the other hand, "age", "BOS stage", "professional status" and "exercise capacity" were found to have a significant impact on self-reported HRQOL in all questionnaires $(p<0.05)$. Analysis of covariance (ANCOVA) allows the inclusion of "age" as an independent variable in the multivariate analysis (Table 5b). Consequently, the significance of the variables "gender", "procedure type" and "professional status" cleared out for SF-36 as well as "professional status" and "underlying disease" for SGRQ ( $>0.05)$. However, statistical significance for "BOS stage" $(p<0.05)$ and "exercise capacity" $(p<0.05)$ on HRQOL remained in all questionnaires independent of patients` age.

\section{DISCUSSION}

This study addresses changes of HRQOL in LTR as a function of subsequent determinants: patient characteristics (gender, age, BMI, time after LTx), clinical determinants (procedure type, underlying disease, BOS stage), sociodemographic data (marital status, education and professional status) and exercise capacity (6MWT). A patient fulfilling the following characteristics was found to gain the best possible HRQOL following LTx: (1) gender: female, (2) age: 23-48 years, (3) BMI: $21-25.2 \mathrm{~kg} / \mathrm{m} 2$ (normal weight), (4) time after LTx: less than 1 year, (5) patients with cystic fibrosis, (6) procedure type: double LTx, (7) professional status: working and (8) physical performance according to 6MWT: 500-800 meters.

The literature shows controversial findings regarding the impact of gender on HRQOL. In accordance with our study results, Goetzmann et al. and Vasiliadis et al. documented less depression and a superior social reintegration after LTx for female patients [12, 13]. In contrast, Rodrigue and colleagues revealed a significantly higher rate of complications and a worse quality of life for female LTR [14].

In our investigation, younger patients between 23 and 48 years showed a significantly better HRQOL in comparison to older LTR. While former studies did not find a correlation between HRQOL and age, the Dutch work group of Vermeulen published a negative impact on HRQOL with advancing age [15]. They conclude that physical deterioration and limited health in older age become more important for self-reported HRQOL.

Our analysis indicated an impact of "time after LTx" on general HRQOL (SF36, PLC) in LTR. In fact, patients within the first year following LTx gained best HRQOL values, followed by long-term survivors beyond 5 years after LTx. We speculate that there might be a tendency whereupon HRQOL reaches a maximum within the first year after the surgical procedure, followed by a decline between 1 and 5 years post-surgery and again an increase beyond 5 years. An explanation for this could be a selection bias: due to progressive mortality of patients suffering from postoperative complications, healthier LTR along with a higher 
self-perceived HRQOL stay alive. Kugler et al. revealed that LTR benefit from the transplant procedure with respect to HRQOL especially during the first year post-transplantation [4]. Furthermore, Rutherford and colleagues revealed that beyond 2 years after LTx - the time frame in which major clinical complications such as BOS may begin to develop and threaten the patients' recovered autonomy - HRQOL declines again [16].

The Munich study results demonstrated a better HRQOL in double LTR versus single LTx. A previous study by Anyanwu et al. examined quality of life of 255 patients following heart-/lung-transplantation (H/LTx) with repeated measure design [17]. In contrast to H/LTx and DLTx patients, SLTx patients were found to have a significantly reduced HRQOL. The authors discussed less improvement in regaining parameters of lung function such as FEV1 and FVC. It is considered proven that DLTx in contrast to SLTx patients recover total lung capacity within one year after surgery $[17,21]$.

LTR are heterogeneous in terms of underlying disease. Therefore the impact of pre-operative disease on postoperative HRQOL was analysed. While COPD- and IPF patients vote their HRQOL as equally good, CF patients stated a significantly better quality with respect to physical domains. Feltrim et al. claimed same results considering an investigation of 50 LTR suffering from four different lung diseases: CF, IPF, COPD and bronchiectasis [18]. CF patients were found to report the best self-perceived quality of well-being. Furthermore, Ricotti and collegues confirmed these findings [5].

It is not clear if underlying disease and therewith type of transplantation procedure may affect HRQOL. Patients with emphysema or fibrosis often receive only a single lung, whereas due to higher infection risk CF patients are typically double transplant recipients [19]. Ramirez and co-workers debated an advantage in HRQOL due to the fact that CF patients are younger by nature of disease history and are usually double LTx recipients accompanied by a greater increase in lung function [20].

In our study population, physical domains of HRQOL were negatively affected by the onset of BOS and are therewith inline with previous findings $[15,22-25]$. Remarkably, the presence of BOS did not affect psychological scales of HRQOL. Ten Vergert and coworkers revealed similar findings in 24 LTR $(B O S \geq 1 ; n=6)$ according to the "Nottingham Health Profile": equally good psychological HRQOL domains independent of BOS [22]. These findings may indicate that LTR may have successfully adapted to their LTx, especially regarding post-operative complications [26].

Out of 152 study patients only $19(12.5 \%)$ LTR in Munich go to work. Hypothetically patients who have a job may have a superior post-operative rehabilitation course associated withan an already existing benefit of HRQOL. Petrucci et al. investigated the return to professional life in 72 LTx- and 79 HTx patients [6]. Despite a positive HRQOL and a good physical condition only 39\% returned to work after the transplantation procedure. If subjective and objective health status was satisfying, other factors may negatively influence the return to work. A lot of LTR are of advanced age, leading to early retirement. In other cases a disability pension does not stringently require the return to professional life.

To analyse the impact of exercise capacity on HRQOL, patients were evaluated by their walking distance. Patients with more than 430 meters described a significantly better HRQOL than patients with less than 430 meters walking distance. To the best of our knowledge no comparable studies could be found to verify our findings. Interestingly, multivariate analysis of variance (ANOVA) revealed a highly significant impact of exercise capacity on HRQOL. This supports the validity of the study result interpretation that quality of life and physical constitution is closely connected. Analysis of covariance (ANCOVA) includes patients`age as a secondary variable in the multivariate analysis. Consequently, the effect of "procedure type", "underlying disease" and "professional status" disappeared in the analysis. This confirms the hypothesis, that LTR with $\mathrm{CF}$ are on the one hand younger and on the other hand due to disease pathogenesis usually double LTx recipients. Both facts may lead to a superior post-operative disease progess, to an active participation in professional life and also to a higher self-perceived quality of life.

There are certain limitations to our study. The recruited subjects are heterogeneous regarding the time frame since the lung transplantation procedure. Moreover, a study design with only one point of measurement does not allow the possibility of statements about the development of HRQOL perceptions by the individual and how they tend to change, especially in those patients with BOS. Given the complex effects of LTx on physical and psychosocial factors, additional outcome measures such as presence of transplant morbidities, e.g. reduced bone mineral density or metabolic syndrome, may also be important to consider in future research.

In conclusion, the results of this evaluation are in line with findings from previous studies and demonstrate the importance of prophylaxis and therapy of BOS as well as improving exercise capacity to further enhance HRQOL following LTx.

\section{CONFLICT OF INTEREST}

The authors confirm that this article content has no conflicts of interest.

\section{ACKNOWLEDGEMENTS}

Declared none.

\section{SUPPLEMENTARY MATERIALS}

Supplementary material is available on the publisher's web site along with the published article.

\section{REFERENCES}


[1] Christie J, Edwards L, Aurora P, et al. Registry of the international Society for Heart and Lung Transplantation: twenty-sixth official adult lung and heart/lung transplantation report-2009. J Heart Lung Transplant 2009; 28: 1031.

[2] Anyanwu A, McGuire A, Rogers C, Murday A. Assessment of quality of life in lung transplantation using a simple generic tool. Thorax 2001; 56: 218-22.

[3] Lanuza D, Lefaiver C, Cabe M, et al. Prospective Study of functional status and quality of life before and after lung transplantation. Chest 2000; 118: 115-22.

[4] Kugler C, Fischer S, Gottlieb J, et al. Health-related quality of life in two hundred-eighty lung transplant recipients. J Heart Lung Transplant 2005; 24: 2262-8.

[5] Ricotti S, Vitulo P, Petrucci L et al. Determinants of Quality of Life after lung transplantation: an Italian collaborative study. Monaldi Arch Chest Dis 2006; 65(1): 5-12.

[6] Petrucci L, Ricotti S, Michelini I, et al. Return to work after thoracic organ transplantation in a clinically-stable population. Eur J Heart Fail 2007; 9(11): 1112-9.

[7] Vasiliadis H, Collet J, Poirier C. Health related Quality of Life determinants in lung transplantation. J Heart Lung Transplant 2006; 25(2): 226-33.

[8] Bullinger M, Kirchberger I. Der SF-36 Fragebogen zum Gesundheitszustand. Handanweisung für die deutschsprachige Fragebogenversion. Hogrefe Verlag: Göttingen 1998.

[9] Siegrist J, Broer M, Junge A. Profil der Lebensqualität chronisch Kranker. Manual zumFragebogen, Beltz Test, Göttingen 1996.

[10] Jones P, Spencer S, Adie S. The St. George`s Respiratory Questionnaire Manual.Version 2.1, St. George`s University of London, London SW170RE, UK 2003.

[11] 11 Ihle F, Neurohr C, Huppmann P, et al. Effect of inpatient rehabilitation on quality of life and exercise capacity in long-term lung transplant survivors: a prospective, randomized study. J Heart Lung Transplant 2011; 30(8): 912-9.

[12] Goetzmann L, Scheuer E, Naef R, et al. Psychosocial situation and physical health in 50 patients $>1$ year after lung transplantation. Chest 2005; 127(1): 166-70.

[13] Vasiliadis H, Collet J, Penrod J, Ferraro P, Poirier C. A costeffectiveness and cost-utility study of lung transplantation. J Heart Lung Transplant 2005; 24(9): 1275-83.
[14] Rodrigue J, Baz M. Are there sex differences in health-related quality of life after lung transplantation for chronic obstructive pulmonary disease? J Heart Lung Transplant 2006; 25(1): 120-5.

[15] Vermuelen K, Van Der Bij W, Erasmus M, TenVergert E. Long term health-related quality of life after lung transplantation: different predictors for different dimensions. J Heart Lung Transplant 2007; 26: 188-93.

[16] Rutherford R, Fisher A, Hilton C, et al. Functional status and Quality of Life in Patients surviving 10 years after Lung transplantation. Am J Transplant 2005; 5(5): 1099-104.

[17] Anyanwu A, McGuire A, Rogers C, Murday A. Assessment of quality of life in lung transplantation using a simple generic tool. Thorax 2001; 56: 218-22.

[18] Feltrim M. The Quality of Life of patients on the lung transplantation waiting list. Transplant Proc 2008; 40(3): 819-21.

[19] Boehler A. Stand der Lungentransplantation heute. Schweiz Med Forum 2004; 4: 436-42.

[20] Ramirez J, Petterson G, Maurer J, et al. Bilateral lung transplantation for cystic fibrosis. The Toronto Lung Transplant Group. J Thorac Cardiovasc Surg 1992; 103(2): 287-93.

[21] Estenne M. Functional respiratory physiology and physiopathology of lung transplant patients. Rev Mal Respir 1996; 13(5): 5-14.

[22] TenVergert E, Essink-Bot M, Geertsma A, van Enckevort P, de Boer $\mathrm{W}$, van der Bij W. The effect of lung transplantation on health-related quality of life: a longitudinal study. Chest 1998; 113(2): 358-64.

[23] Van Den Berg J, Geertsma A, Van Der Bij W, et al. Bronchiolitis obliterans syndrome after lung transplantation and health-related quality of life. Am J Respir Crit Care Med 2000; 161: 1937-41.

[24] Gerbase M, Soccal P, Spiliopoulos A, Nicod L, Rochat T. Long term health-related quality of life and walking capacity of lung recipients with and without bronchiolitis obliteranssyndrome. J Heart Lung Transplant 2008; 27: 898-904.

[25] Künsebeck H, Kugler C, Fischer S, et al. Quality of life and bronchiolitis obliterans syndrome in patients after lung transplantation. Prog Transplant 2007 17(2): 136-41.

[26] Freyberger H, Brinkert M. Die supportiv-psychostherapeutische Arbeitsbeziehung bei psychosomatischen Patienten und chronisch körperlich Kranken. In: Strauß B, Meyer A Eds. Psychoanalytische Psychosomatik: Schattauer 1994; pp. 179-192.

Received: April 15, 2013 